\section{Non-metastatic squamous cell carcinoma in two Hermann's tortoises (Testudo hermanni)}

\author{
Marie-Charlotte von Deetzen, 1 \\ Kerstin Müller,2 \\ Leo Brunnberg, 2 Robert Klopfleisch ${ }^{1}$ \\ 1Department of Veterinary Pathology; \\ 2Small Animal Clinic, Freie University \\ Berlin, College of Veterinary Medicine, \\ Berlin, Germany
}

\begin{abstract}
Squamous cell carcinomas (SCC) are malignant tumors of the epidermal cells with varying degrees of keratinocyte differentiation. They are common tumors in mammalian and avian species but there are, however, only two description of SCC in tortoises. In this case report we describe two cases of non-metastatic squamous cell carcinomas of the carapax and the plastron in Hermann's tortoises with evidence of humoral hypercalcemia of malignancy (HHM) in one case. HHM is thought to be associated with SCC in mammals due to de novo secretion of parathyroid hormone-related protein (PTHrP) by the tumor cells or tumor induced osteolysis but has not been described in reptiles so far.
\end{abstract}

\section{Introduction}

Due to an increased life expectancy of nondomestic animals in captive care tumors are recorded more often, when compared with free ranging animals. ${ }^{1}$ In reptiles, neoplastic diseases are observed in all three major orders with snakes having the highest prevalence, followed by lizards, chelonians and crocodilians. ${ }^{2}$ The skin is one of the most common tumor sites in reptiles with frequent descriptions of fibrosarcomas, papillomas and pigment cell tumors 3,4 Squamous cell carcinomas (SCC) are most frequently observed in snakes and lizards. ${ }^{5,6}$ Within the order of testudines several cases of SCC have been described in turtles. $27-11$ However, in the family testudinidae (tortoises) only two cases of SCC has been reported so far, in a Brazilian giant tortoise (Chelonoidis denticulata, formerly Geochelone denticulata) ${ }^{12}$ and in a Hermann's tortoise. ${ }^{13}$ The skin is the most common site to develop SCC in chelonians but oral, 6,12 and coelomic ${ }^{8}$ SCC can also be present. Metastatic spread of SCC in reptiles is rare and has been reported in only three cases of turtles. 7,9

Humoral hypercalcemia of malignancy
(HHM) is a paraneoplastic syndrome commonly associated with several mammalian tumors but to the authors knowledge it has not been described in reptiles. HHM is caused by de novo secretion of parathyroid hormone-related protein (PTHrP) by the tumor cells or thought to be associated with tumor induced osteolysis. ${ }^{14}$

The present case report describes two cases of SSC in Hermann's tortoises without metastatic spread but in one case with clinical and pathologic lesions similar to HHM in mammals.

\section{Case Report}

\section{Anamnesis and clinical findings}

Animal \#1, a 28 year old male Hermann's tortoise (Testudo hermanni), was presented due to a profound swelling at the tail base for several weeks. The single kept tortoise lived on a balcony during summer and was running free in the apartment during winter. Hibernation was not performed. Salad and chicory were the main components of the tortoise's nutrition. Neither a heating place or ultraviolet light nor vitamin or mineral supplements were provided for the animal. The clinical examination revealed a $1.13 \mathrm{~kg}$ apathetic and weak animal with pale mucous membranes and a firm swelling involving the right tail basis. Beside a hypercalcemia (ionized calcium $2.53 \mathrm{mmol} / \mathrm{L}$, reference range 1.19 - 1.42 $\mathrm{mmol} / \mathrm{L}^{15}$ ) no other blood alterations were evident. Radiographs gave no indication of any abnormality, whereas computed tomography showed an extensive soft tissue mass of the right caudal coelom causing also osteolysis of the caudodistal right carapax (Figure 1 and Figure 2). During fine needle aspiration a sanguinary fluid was attained, but cytological examination gave no indication of the type of the neoplasm. The owner elected euthanasia due to the bad clinical condition of the animal and the poor prognosis.

Animal \#2 was an approximately 55 year old, $1.2 \mathrm{~kg}$, male Hermann's tortoise (Testudo hermanni). The tortoise developed ulceration on the left, caudal quadrant of the plastron over a period of 6 to 7 months. The ulcer was treated locally with antibiotics. The animal died spontaneously and was submitted for necropsy.

\section{Gross pathology}

On post mortem examination both tortoises were cachectic. Animal \#1 had a solid and grey to yellow mass with a size of $7.0 \times 5.0 \times 3.0 \mathrm{~cm}$, expanding from the right side of the tail to the caudal right coelom involving the caudal inner side of the carapax (Figure 3). The urinary sac was distended by approximately $40 \mathrm{~mL}$ clear, yellow, slightly gelling urine. The digestive tract was empty. The parathyroids were unre-
Correspondence: Robert Klopfleisch, Freie Universität Berlin, Institute of Veterinary Pathology, Robert-von-0stertag-Str. 15, 14163 Berlin, Germany.

Tel. +49.30.83862450 - Fax: +49.30 .83862522 .

E-mail: robert.klopfleisch@fu-berlin.de

Key words: tortoise, reptile, squamous cell carcinoma.

Acknowledgement: we thank Rüdiger Obst for his technical assistance during the computed tomography.

Received for publication: 10 October 2011.

Revision received: 2 January 2012.

Accepted for publication: 3 January 2012.

This work is licensed under a Creative Commons Attribution NonCommercial 3.0 License (CC BYNC 3.0).

(OCopyright M. von Deetzen et al., 2012

Licensee PAGEPress srl, Italy

Veterinary Science Development 2012; 2:e5 doi:10.4081/vsd.2012.e5

markable.

Animal \#2 had a large perforating ulcer, measuring $8.0 \times 5.0 \mathrm{~cm}$ in the left, caudal quadrant of the plastron with irregular borders (Figure 4). On cut section, the ulcer was encircled by a dense, irregular, grayish mass with central necrosis and mild to severe reactive new bone formation. Besides, both knee joints had mild, multifocal degenerative joint disease with loss of joint cartilage. The faeces were formed and contained numerous nematodes consistent with Oxyuris spp.

\section{Histopathology}

Samples were collected from different organs and tissues, fixed in $4 \%$ neutral buffered formalin, processed by routine methods, embedded in paraffin wax, sectioned (1 $\mu \mathrm{m})$ and stained with haematoxylin and eosin (HE). The samples of the masses were also stained with Ziehl Neelsen and a periodic acid Schiff (PAS) reaction was performed. The bony and keratinized parts of the carapax of animal \#1 were decalcified using 25\% EDTA for eleven weeks and subsequently treated with neutral chlordioxid for further six weeks.

Histologically, the mass of animal \#1 was identified as a moderately differentiated SCC. The tumor was moderately cellular with predominant necrotic areas. The tumor cells were arranged in nests and packets, supported by fine fibrovascular stroma. The mitotic rate was moderate with up to three mitotic figures per high power field and occasionally atypical mitotic figures were found. In one location the tumor cells were severely infiltrating and 


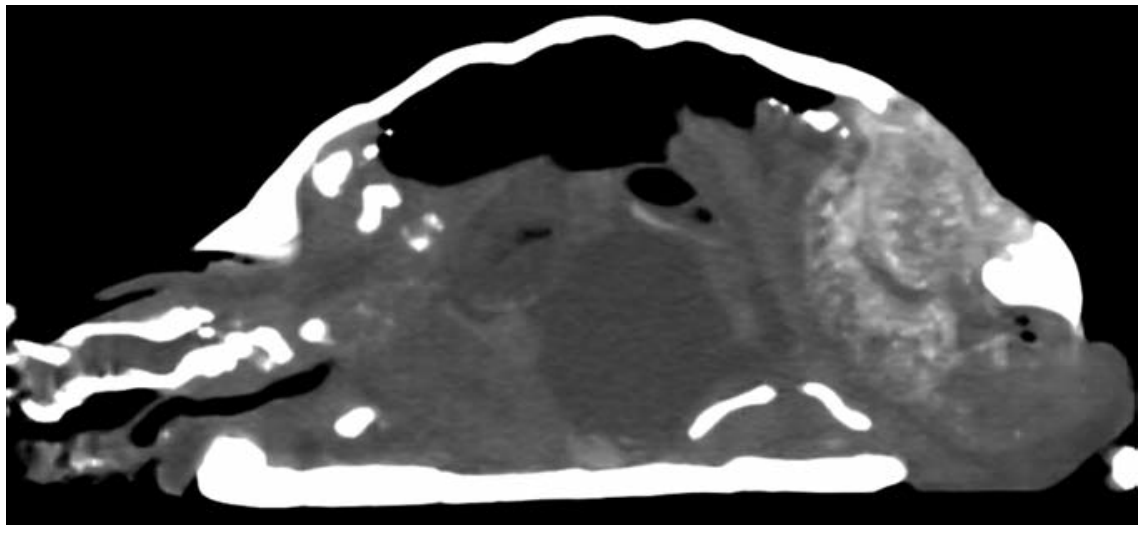

Figure 1. Sagittal computed tomography of the Herrmann's tortoise (Testudo hermanni, animal \#1) with squamous cell carcinoma of the soft tissue right at the right tail basis. Note the osteolytic area of the carapax.

replacing the lamellar bone of the carapax bone plates (Figure 5). Adjacent to this area a severe, subacute, multifocal, heterophilic osteomyelitis was evident. Multifocal within the tumor keratin pearls were evident and individual cells often showed irregular keratinization (Figure 6). The extensive coagulative necrosis was mostly admixed with moderate numbers of heterophils and showed multifocal sites of mineralization and occasionally evidence of basophilic coccoid bacteria. There was infiltration of the adjacent tissue by tumor cells but neither blood nor lymphatic vessels contained tumor cells. Neither PAS-positive fungi nor acid fast bacteria could be detected. Furthermore a mild, subacute, multifocal, interstitial nephritis with mild tubular mineralization and dilation was identified. A moderate, subacute, multifocal, heterophilic urocystitis was apparent. Within the stomach moderate, multifocal mineralization was evident. Brain, lung, heart, liver, digestive tract and skeletal muscle were unremarkable.

The histological examination of the ulcerated mass of animal \#2 was also identified as a moderately differentiated, infiltrative SCC without invasion of surrounding vessels. The polygonal to fusiform cells showed mostly distinct cell borders and moderate amounts of eosinophilic, homogenous cytoplasm. The mitotic rate was low with less than one mitotic figure per high power field. Individual cells revealed irregular keratinization but only few keratin pearls were visible. There were multifocal small areas of coagulative necrosis admixed with few lymphocytes and plasma cells. Within the mass multifocally basophilic, coccoid bacteria and occasionally mineralization were evident. Around the nests of tumor cells there was a desmoplastic reaction in the surrounding tissue. Few PAS-positive fungal hyphae were present besides the areas of necrosis. Acid fast bacteria were not detectable. Metastatic tumor cells were not present in lung, heart, liver, digestive tract or skeletal muscle.

In summary, macroscopic and histologic findings lead to the diagnosis of a non-metastatic squamous cell carcinoma in both cases.

\section{Discussion}

Here, we describe two cases of non-metastatic squamous cell carcinoma in Hermann's tortoises. Squamous cell carcinomas (SCC) are rarely reported to occur in the order testudines. Two reports identified this neoplasm in testudinidae (tortoises): A Brazilian giant tortoise (Geochelone denticulata) ${ }^{12}$ and a Hermann's tortoise (Testudo hermanni) ${ }^{13-15}$ whereas eight cases of squamous cell carcinomas were described in turtle species others than testudinidae: An Indian black turtle (Melanochelys trijuga), 11 an European pond turtle (Emys orbicularis), ${ }^{7}$ an Eastern box turtle (Terrapene carolina), ${ }^{8}$ a Red-eared slider (Trachemys scripta elegans), 12 a Common snake-necked turtle (Chelodina longicollis), a Spiny soft shell turtle (Apalone spinifera spinifera) ${ }^{10}$ and two Loggerhead sea turtles (Caretta caretta). ${ }^{9}$ The neoplasm appeared at different locations, mostly the skin 10,11 but also included the oral cavity 12 and the coelom. ${ }^{8}$ Metastasis has not been reported in tortoises and was not present in the two cases reported here. In a pond turtle with SCC of the intermandibular space metastases were found in the liver. ${ }^{7}$ Furthermore, two loggerhead sea turtles with multiple SCCs showed metastases in several tissues. ${ }^{9}$ Other reports of SCC in reptile species did not mention metastasis. ${ }^{16}$ This is in contrast to the situation in mammals where metastasis is a common phenomenon in patients with oral but also with cutaneous SCC. 17

Animal \#1 had a hypercalcemia of unknown origin. The main causes of hypercalcemia in animals are increased calcium mobilization from bone, increased calcium absorption from

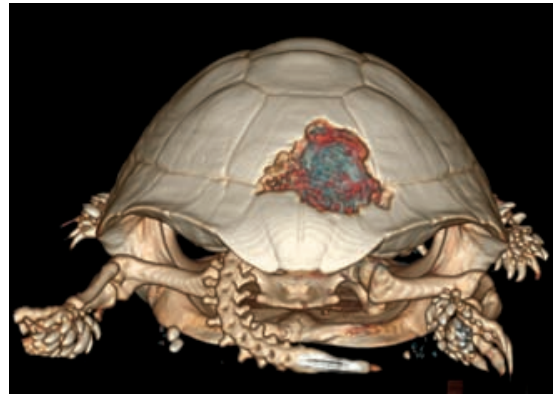

Figure 2. 3-D-reconstruction of the caudal aspect of the Herrmann's tortoise (Testudo hermanni, animal \#1 with squamous cell carcinoma of the soft tissue right at the right tail basis to evaluate the expansion of the osteolytic area.

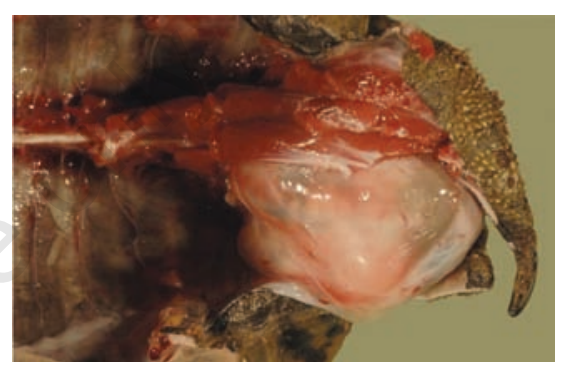

Figure 3. Caudal plastron of the Herrmann's tortoise (Testudo hermanni) with squamous cell carcinoma of the soft tissue right at the right tail basis (animal \#1). At the right side of the tail basis and extending into the caudal right coelom there was a solid, firm mass mass.

the intestine, decreased urinary excretion of calcium due to renal failure or increased protein-bound calcium or hypercalcemia of malignancy (HHM). ${ }^{18}$ Increased protein bound calcium could be excluded in the present case because free calcium was measured. Primary hyperparathyreoidism was not likely to be the cause of the increased free calcium since there were no clinical or macroscopic observable lesions in the parathyroids. Secondary renal hyperthyreoidism was excluded since the interstitial nephritis in this case was only mild and subacute. Additionally, phosphorus concentrations in the blood were within reference ranges. The animal neither received any vitamins, nor had contact to plants or substances known to have vitamin D activity, therefore a hypervitaminosis D as the cause of hypercalcemia was unlikely. The tortoise did not have any granulomatous inflammation which may lead to Vitamin D synthesis by macrophages. ${ }^{18}$

Exclusion of this common causes of hypercalcemia in this case leads to the potential diagnosis of humoral HHM due to an increased synthesis of PTHrP by the tumor cells or tumorinduced osteolysis of the carapax. ${ }^{18}$ Unfortunately, methods to reliably measure 


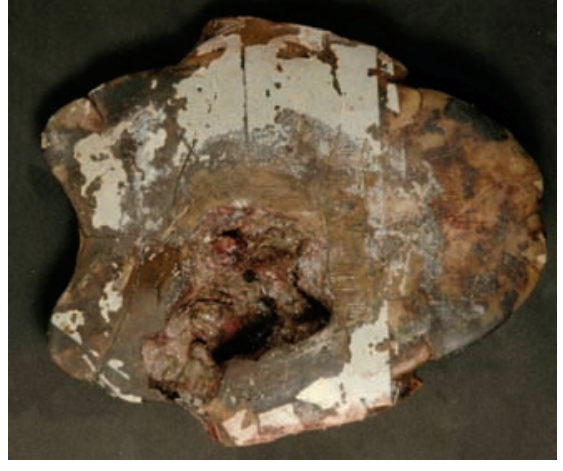

Figure 4. Plastron Plastron of the Hermann's tortoise (Testudo hermanni) with squamous cell carcinoma of the plastron (animal \#2). A focal extensive ulcer was visible in the left, caudal quadrant of the plastron with irregular borders and extending deep into the coelomic cavity.

the blood and tissue levels of PTHrP in reptile species are not available. In previous reports, hypercalcemia has not been described in reptiles with SCC but can be observed in humans cats and dogs with HHM. ${ }^{19-21}$ The basis of the HHM in some of these patients could be associated with PTHrP synthesis by tumor cells, ${ }^{22,23}$ whereas in others PTHrP synthesis was not identified. ${ }^{24}$

In summary, SCC is a rare tumor in tortoises, although it is described in a few cases. Both tumors appeared at sites with little exposure to UV light when compared to other regions of the integument, indicating that radiation may not be associated with SCC induction in this species. Both animals were older than 20 years, suggesting that SCC genesis may be associated with age. In addition, at least in one of the animals a hypercalcemia of malignancy was diagnosed, although its exact molecular mechanism remains unclear.

\section{References}

1. Anderson ET, Kennedy-Stoskopf S, Sandy JR, et al. Squamous cell carcinoma with vascular invasion in a Diamondback Rattlesnake (Crotalus Adamanteus). J Zoo Wildl Med 2010;41:745-8.

2. Garner MM, Hernandez-Divers SM, Raymond JT. Reptile neoplasia: a retrospective study of case submissions to a specialty diagnostic service. Vet Clin North Am Exot Anim Pract 2004:653-71.

3. Mader DR. Reptile medicine and surgery. Philadelphia: W.B. Saunders; 1996.

4. Ackermann DL. Atlas der Reptilienkran-

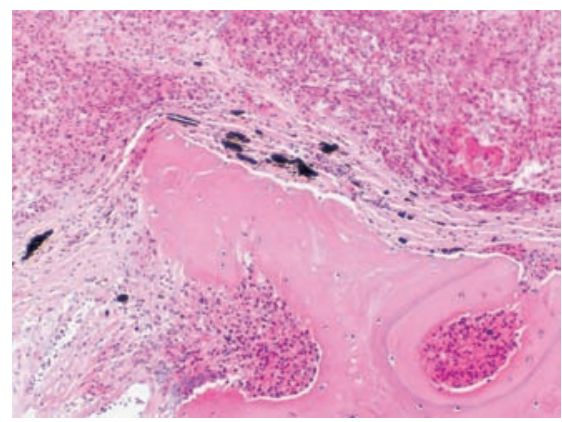

Figure 5. Squamous cell carcinoma and adjacent desmoplastic reaction reaction of the Herrmann's tortoise (Testudo hermanni) with squamous cell carcinoma of the soft tissue right at the right tail basis (animal \#1). Tumor cells were infiltrating and replacing the lamellar bone of the carapax bone plates.

kheiten. Bede-Verlag GmbH; 2000.

5. Jacobson ER. Neoplastic diseases. San Diego: Academic Press; 1981.

6. Machotka SV. Neoplasia in reptiles. New York: Plenum Press; 1984.

7. Billups LH, J.C.Harshbarger. Naturally occuring neoplastic diseases. XI. Reptiles. In: Melby EC, Altman NH, editors. Handbook of laboratory animal science. Cleveland: CRC Press; 1976. p. 343-56.

8. Greenacre CB, Roberts R. Effect of strontium-90 on squamous cell carcinoma in an eastern box turtle (Terrapene carolina); discussion of alternative treatment modalities. 3rd International virtual conference in veterinary: diseases of reptiles and amphibians. Athens: Georgia University; 2000.

9. Orós J, Tucker S, Fernandez L, Jacobson ER. Metastatic squamous cell carcinoma in two loggerhead sea turtles Caretta caretta. Dis Aquat Organ 2004;58:245-50.

10. Sykes JM, Trupkiewicz JG. Reptile neoplasia at the Philadelphia Zoological Garden, 1901-2002. J Zoo Wildl Med 2006;37:11-9.

11. Cowan DF. Diseases of captive reptiles. J Am Vet Med Ass 1968;153:848-59.

12. Frye FL. Biomedical and surgical aspects of captive reptile husbandry. 2nd ed. Melbourne: Krieger Publishing; 1991.

13. Gabrisch K. 4th international colloquium on pathology and medicine of reptiles and amphibians. Bad Nauheim: DVG; 1991.

14. Fereidooni F, Horvath E, Kovacs K. Humoral hypercalcemia of malignancy due to bipartite squamous cell/small cell carcinoma of the esophagus immunoreactive for parathyroid hormone related protein. Dis Esophagus 2003;16:335-8.

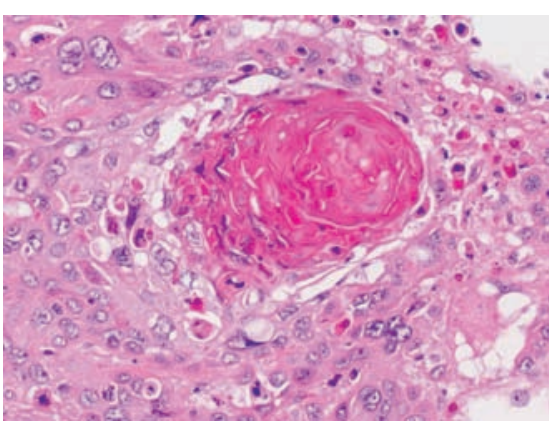

Figure 6. Squamous cell carcinoma of the soft tissue right at the right tail basis tumor cells of the Herrmann's tortoise (Testudo hermanni) (Testudo hermanni) (animal \#1). Tumor cells showed irregular keratinization and were forming horn pearls. In some locations a mild infiltration of heterophilic granulocytes was evident.

15. Eatwell K. Calcium and phosphorus values and their derivatives in captive tortoises (Testudo species). J Small Anim Pract 2010;51:472-5.

16. Mauldin GR, Done LB. Oncology. In: Mader DR, editor. Reptile medicine and surgery. Toronto: Elsevier 2006. p. 299-322.

17. Meleo KA. Tumors of the skin and associated structures. Vet Clin North Am Small Anim Pract 1997;27:73-94.

18. Stockham SL, Scott MA. Fundamentals of veterinary clinical pathology. Oxford: Blackwell Publishing; 2008.

19. Thomas M, Schneider W. Differentialdiagnose und Therapie tumorbedingter Hypercalcamien. Dtsch Med Wochenschr 1989; 114:1576-81.

20. Savary KC, Price GS, Vaden SL. Hyper-calcemia in cats: a retrospective study of 71 cases (1991-1997). J Vet Int Med 2000;14: 184-9.

21. Grain E Jr., Walder EJ. Hypercalcemia associated with squamous cell carcinoma in a dog. J Am Vet Med Ass 1982;181:165-6.

22. Rosol TJ, Nagode LA, Couto CG, et al. Parathyroid hormone (PTH)-related protein, PTH, and 1,25-dihydroxyvitamin D in dogs with cancer-associated hypercalcemia. Endocrinology 1992;131:1157-64.

23. Tannehill-Gregg S, Kergosien E, Rosol TJ. Feline head and neck squamous cell carcinoma cell line: characterization, production of parathyroid hormone-related protein, and regulation by transforming growth factor-beta. In Vitro Cell Dev Biol Anim 2001;37:676-83.

24. Klausner JS, Bell FW, Hayden DW, et al. Hypercalcemia in two cats with squamous cell carcinomas. J Am Vet Med Ass 1990; 